\title{
REVISTAMATĒRIA
}

\section{Hydroxyethyl Cellulose Acrylamide Graft Polymer-Bentonite Nanocomposites Synthesis, Characterization and Properties}

\author{
Songze Liao ${ }^{1,2}$, Yi Pan $^{1}$, Shuangchun Yang ${ }^{1}$, Guangzhi Liao ${ }^{3}$, \\ Minglei $\mathrm{Xu}^{1}$, Dinar Nigmatullin ${ }^{4}$
}

\author{
${ }^{1}$ College of Oil and Gas Engineering, Liaoning Petrochemical University, CEP 113001, Fushun, Liaoning, China \\ ${ }^{2}$ Beijing Key Laboratory of Unconventional Natural Gas Geology Evaluation and Development Engineering, China \\ University of Geosciences, CEP 100089, Beijing, China \\ ${ }^{3}$ State Key Laboratory of Petroleum Resources and Prospecting, China University of Petroleum, CEP 102200, Beijing, \\ China. \\ ${ }^{4}$ Institute of International Education, Liaoning Petrochemical University, CEP 113001, Fushun, Liaoning, China \\ e-mail: 1sz_pj@163.com, panyi_bj@126.com,panhongxiang@126.com, liaoguangzhi@cup.edu.cn, \\ xml1960160966@126.com,xDinarx@mail.ru
}

\begin{abstract}
Bentonite is the most important material used in oil and gas field drilling operations. However, the properties of natural bentonite cannot meet the requirements of bentonite for drilling. Therefore, researchers pay much attention to the modification of bentonite. The hydroxyethyl cellulose-acrylamide graft polymer was synthesized by microwave assisted, and the bentonite composite based on the graft polymer was prepared. FTIR, XRD and SEM results show that the polymer exists between the layers and the surface of the bentonite. Research on the bentonite composite showed that the yield point and filtration properties of bentonite composite are higher than natural bentonite at 90 to 150 celsius. The composite yield point / plastic viscosity ratio is more than 0.6 and the minimum fluid loss is only $9.3 \mathrm{ml}$, which can meet the requirements of drilling-grade bentonite. This material has the potential to be a candidate for drilling applications.
\end{abstract}

Keywords: bentonite composite, hydroxyethyl cellulose, acrylamide, microwave-assisted polymerization, solution intercalation.

\section{INTRODUCTION}

Bentonite is the basic material for drilling oil and gas wells, but natural bentonite often cannot meet the needs of drilling. [1] The rheology and fluid loss of bentonite will greatly affect the properties of drilling mud, then affect the efficiency of drilling tools and the cycle of drilling operations. [2, 3] It can be seen from the standards published by American Petroleum Institute (API) that the bentonite mud with the apparent viscosity $\left(\eta_{A}\right)$ of more than $15 \mathrm{mPa} \cdot \mathrm{s}$ and the fluid loss of less than $15 \mathrm{ml}$ can meet the drilling operations. [4] Therefore, it has became the main goal for researchers to modify natural bentonite and improve its properties.

Previously, some researchers have modified bentonite with polymers to prepare polymer/bentonite composite, and have gotten good results. Jain et al. [5] prepared a polyacrylamide/clay nanocomposite (PANC) by radical polymerization. The research has shown that polyacrylamide (PHPA) has better compatibility with bentonite, and PANC has higher thermal stability than PHPA. However, the rheology and filtration performance of the system will decrease if the amount of PHPA is high. In addition, PANC also shows good results in terms of inhibiting shale hydration and enhancing wellbore stability. Mohamadian et al. [6] prepared poly (styrene-methyl methacrylate-acrylic acid)/nano-bentonite composite by microemulsion polymerization. The bentonite composite can still maintain a strong ability to control fluid loss under high temperature $\left(93^{\circ} \mathrm{C}\right)$. Compared with the drilling mud mixed by polymer, the fluid loss of the drilling mud prepared by bentonite composite is reduced by about $28 \%$.

Hydroxyethyl cellulose is a clean, renewable polymer.[7] It is widely used in oilfield mining, building 
materials, medicine, industrial wastewater treatment, biological engineering and other fields. [8-12] Hydroxyethyl cellulose can be used as a thickener and a fluid loss reducer in drilling operations. [13] However, there are limits to application of hydroxyethyl cellulose at high temperatures due to the existence of ether bonds. [14] And the use of hydroxyethyl cellulose alone in the drilling fluid generally does not exceed $110^{\circ} \mathrm{C}$. [15] Some research have shown that after grafting acrylamide, the length of hydroxyethyl cellulose molecular chain will increases, and the temperature resistance is higher than the samples before grafting. [16] Besides, the introduced adsorption group can provide stronger adsorption performance for hydroxyethyl cellulose. [17] Previously, some scientists have demonstrated the possibility of combining cellulose or its derivatives with bentonite to prepare composite materials. Zhou et al. [18] prepared LRD/HEC layered composite by self-assembly using hydroxyethyl cellulose and clay as raw materials. Adair et al. [19] successfully prepared superabsorbent composites (SAPCs) by in-situ polymerization using polyacrylamide, hydroxyethyl cellulose, and bentonite. In summary, compounding cellulose and its derivatives with bentonite may become a new research direction for composite materials in the field of drilling.

The purpose of this research is to synthesize HEC-AM/bentonite nanocomposites by hydroxyethyl cellulose-acrylamide graft polymer through polymer solution intercalation. The optimum preparation conditions of bentonite composites were determined. The successful preparation of polymer/bentonite composites was demonstrated with the assistance of XRD, FTIR and SEM analysis. In the end, the rheology and filtration properties of the composites at different high temperatures were evaluated.

\section{EXPERIMENTAL}

\subsection{Materials}

Natural Na-bentonite was provided by Shengshou Mineral Products Co., Ltd., Lingshou County, Hebei. The composition of bentonite is: $\mathrm{SiO}_{2} 69.3 \%, \mathrm{Al}_{2} \mathrm{O}_{3} 15.5 \%, \mathrm{Fe}_{2} \mathrm{O}_{3} 2.8 \%, \mathrm{CaO} 1.9 \%, \mathrm{MgO} 1.6 \%, \mathrm{Na}_{2} \mathrm{O} 0.8 \%$, $\mathrm{K}_{2} \mathrm{O} 1.4 \%, \mathrm{TiO}_{2} 0.2 \%$. The viscosity of the hydroxyethyl cellulose used at $25^{\circ} \mathrm{C}$ is $1500-2500 \mathrm{mPa} \cdot \mathrm{s}$, provided by Shanghai Yien Chemical Technology Co., Ltd., China. Acrylamide (99\%) was purchased from Shanghai Mokai Biotechnology Co., Ltd. in China. Ammonium persulfate (AR $\geq 98 \%$ ), sodium bisulfite (AR), sodium hydroxide $(\mathrm{AR} \geq 96 \%)$ and ethanol $(75 \%)$ were provided by China National Pharmaceutical Group Chemical Reagent Co., Ltd. And acetone (AR $\geq 99.5 \%$ ) was provided by China Liaoning Xinxing Reagent Co., Ltd. Deionized water was used throughout the experiment.

\subsection{Synthesis and optimization of nanocomposites}

HEC (1g) and AM ( $4 \mathrm{~g})$ were dispersed in $54 \mathrm{ml}$ of deionized water and stirred well on a magnetic stirrer. The sodium hydroxide solution was added dropwise and the $\mathrm{pH}$ was continuously tested to $\mathrm{pH}=7$. The stirred solution was poured into a three-necked flask. Then $0.03 \mathrm{~g}$ of ammonium persulfate and $0.03 \mathrm{~g}$ of sodium bisulfite were added in the flask. And the container was put in the MAS-II microwave synthesis reaction instrument (Shanghai Xinyi Microwave Chemical Technology Co., Ltd., China). The initial parameters of the synthesis reaction were preset to $40^{\circ} \mathrm{C}, 60 \mathrm{~h}, 200 \mathrm{~W}$, and nitrogen was passed. To ensure sufficient reaction, magnetic stirring was maintained during the synthesis. After the timing was over, a transparent gel-like liquid was obtained. After standing to normal temperature, the reaction was precipitated with ethanol and washed several times. After drying the precipitate to a constant weight in a vacuum state at $70^{\circ} \mathrm{C}$, the precipitate was purified in a Soxhlet extractor for $10 \mathrm{~h}$ with acetone. Finally, the precipitate is dried to constant weight and ground into a powder in a YXQM planetary ball mill (MITR Instrument Equipment Co., Ltd., China).

Na-bentonite was dispersed in deionized water. After the dispersion was fully stirred, $5 \mathrm{wt} \%$ (relative to the mass of bentonite) of HEC-AM was added, and the mixture was vigorously stirred for $2 \mathrm{~h}$ at a speed of $10 \times 10^{3} \mathrm{rpm}$. Finally, it is dried to constant weight through a drying box, and then ground again to obtain a HEC-AM/bentonite composite. Figure 1 illustrates the steps involved in the development of HEC-AM/bentonite nanocomposites.

According to the recommended testing and evaluation methods of "APISPEC13A-2010", 22.5g of the composite was dispersed in $350 \mathrm{ml}$ of deionized water, stirred for $5 \mathrm{~min}$, and then left at room temperature for 24h. [20] The fluid loss and rheology of the base mud were tested after standing. After recording the test data, equations 2, 3, and 4 are used to calculate the yield point / plastic viscosity ratio (RYP) of the base mud. [21] And the fluid loss (FL) and RYP are used as indicators to optimize the variable $\mathrm{pH}, \mathrm{HEC} / \mathrm{AM}$ ratio, initiator concentration, temperature, time, and reactant monomer concentration. 


$$
\begin{aligned}
& \eta_{\mathrm{A}}=R_{600} / 2 \\
& \eta_{\mathrm{P}}=R_{600}-R_{300} \\
& \eta_{Y}=R_{300}-\eta_{\mathrm{P}} \\
& R Y P=\eta_{\mathrm{Y}} / \eta_{\mathrm{P}}
\end{aligned}
$$

where $\eta_{\mathrm{A}}$ is apparent viscosity, $\mathrm{mPa} \cdot \mathrm{s}, \eta_{\mathrm{P}}$ is plastic viscosity, $\mathrm{mPa} \cdot \mathrm{s}, \eta_{\mathrm{Y}}$ is yield point, $\mathrm{Pa}$, RYP is yield point / plastic viscosity ratio, $R_{300}$ and $R_{600}$ are the values for viscometer speed of 300 and $600 \mathrm{r} / \mathrm{min}$, respectively.

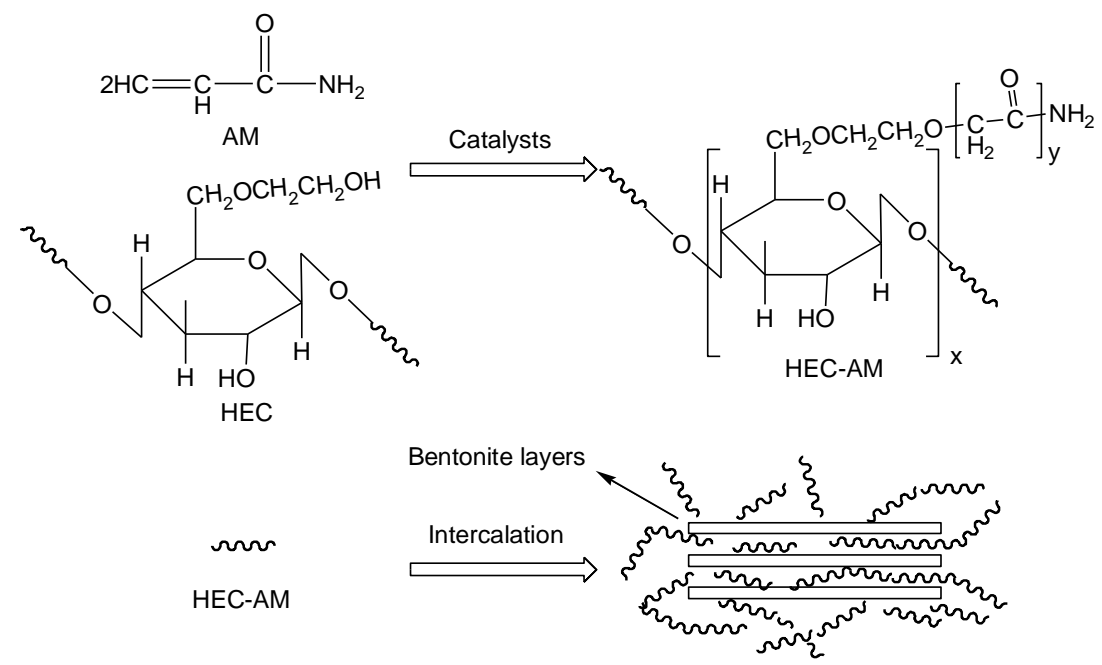

Figure 1: Possible reaction mechanism that occurs during the preparation of HEC-AM/bentonite

\subsection{Characterization}

The Fourier Transform Infrared (FTIR) spectrometer Spectrum GX provided by Perkin-Elmer (Massachusetts, USA) was used to detect the chemical bonds of the composites. The experimental samples were scanned 64 times for each by using $\mathrm{KBr}$ pellet method. In order to determine the ratio of polymer to bentonite in the composite, a D / max RB X-ray diffractometer (Rigaku, Japan) was used to carry out the product phase of the composite with the added polymer content of $3 \mathrm{wt} \%$, $4 \mathrm{wt} \%$, $5 \mathrm{wt} \%$, and $6 \mathrm{wt} \%$ Measurements: $\mathrm{Cu} \mathrm{K \alpha}$ radiation $(\lambda=0.15418 \mathrm{~nm})$ tube pressure: $40 \mathrm{Kv}$, tube flow: $100 \mathrm{~mA}$, continuous scanning method, step size $0.02^{\circ}$, scan rate $6^{\circ}(2 \theta) / \min$. To determine the position of the peaks and the change in the spacing of the bentonite layer, the diffraction pattern was used in conjunction with the MDI Jade software. The morphological properties of Na-bentonite and the composite were characterized by a field emission scanning electron microscope SU8010 (HITACHI, Japan).

\subsection{Performance evaluation}

A GRL-3BX roller heating furnace (Qingdao Hongxiang Petroleum Machinery Manufacturing Co., Ltd.) was used to simulate the high temperature working condition of the base slurry, and the base mud prepared by the above method was aged. The ZNN-D6 rotational viscometer and ZNS-3 medium pressure loss tester were used to test the rheological properties and fluid loss of aged natural bentonite and bentonite composite. 


\section{RESULTS AND DISCUSSION}

\subsection{Synthesis of HEC-AM/bentonite}

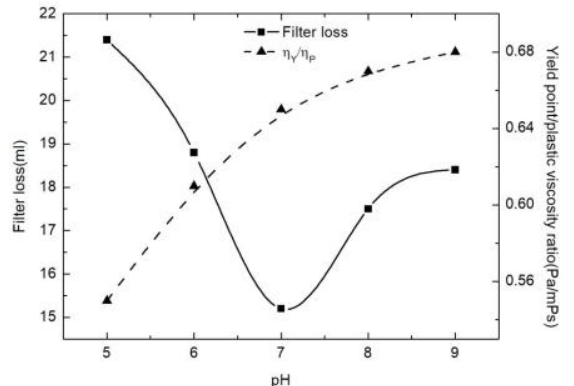

(a)

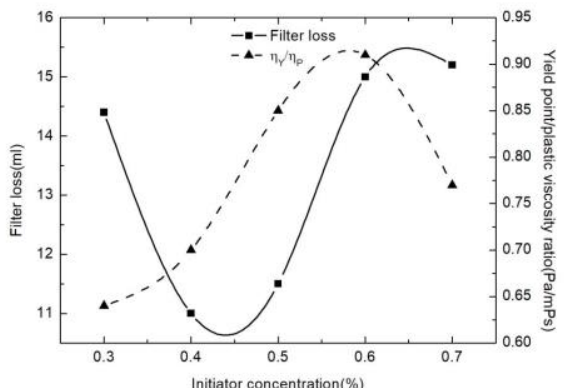

(c)

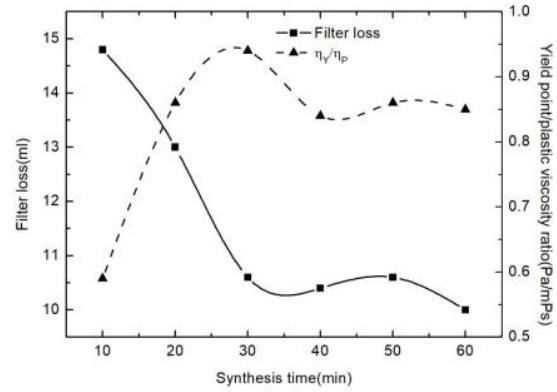

(e)

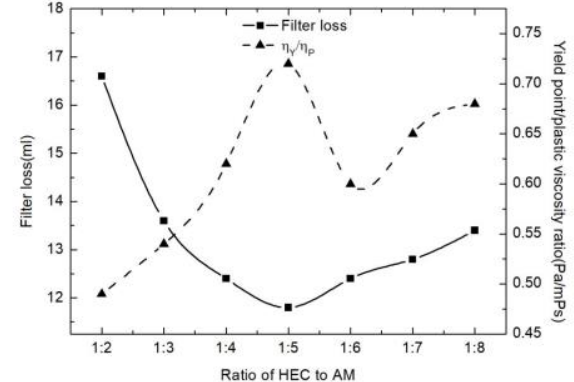

(b)

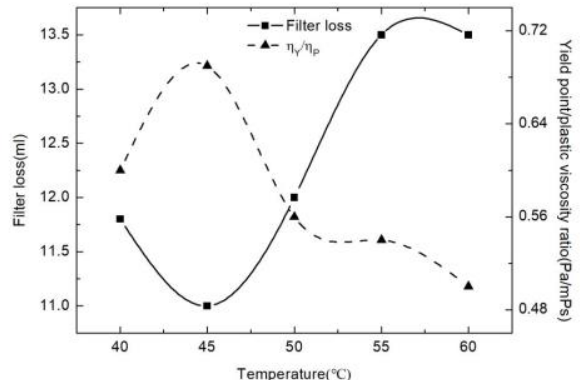

(d)

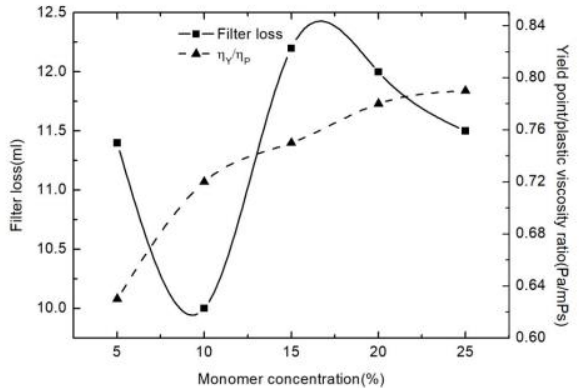

(f)

Figure 2: Optimization of preparation conditions of HEC-AM/Bentonite nanocomposite: (a) pH, (b) ratio of HEC to AM, (c) initiator concentration, (d) temperature, (e) systhesis time and (f) monomer concentration

The $\mathrm{pH}$ of the system was adjusted with a sodium hydroxide solution, the mass fraction of the monomer was fixed at $10 \mathrm{wt} \%$, the mass ratio of HEC to AM was 1: 4, the amount of initiator was $0.5 \mathrm{wt} \%$ of the mass of the monomer, and the reaction was performed at $60^{\circ} \mathrm{C}$ for $1 \mathrm{~h}$. HEC-AM/bentonite composite was prepared by adding $5 \mathrm{wt} \%$ HEC-AM in bentonite. The effect of $\mathrm{pH}$ on fluid loss and RYP are shown in Figure 2a. As the reaction conditions changed from acidic to basic, the fluid loss decreased firstly, then increased, and reached a minimum at $\mathrm{pH}=7$. It was clear that $\mathrm{RYP}$ went up, but the growth rate decreased when $\mathrm{pH}>7$. When the $\mathrm{pH}$ was low, the high concentration of $\mathrm{H}^{+}$would inhibit the activity of the initiator, which was not conducive to polymer synthesis. And the bentonite composite cannot control the fluid loss effectively. At high $\mathrm{pH}$, the decomposition of the initiator was promoted, resulting in the molecular weight of polymer is small. The fluid loss of the mud also increased. [22] Finally, it was determined that the reaction was performed under an environment of $\mathrm{pH}=7$.

Polymerization was carried out with different mass ratios HEC and AM. It was set that $\mathrm{pH}=7$, monomer mass fraction $10 \mathrm{wt} \%$, initiator dosage $0.5 \mathrm{wt} \%$, and reacted at $60^{\circ} \mathrm{C}$ for $1 \mathrm{~h}$. The effect of the HEC to AM ratio is shown in Figure $2 \mathrm{~b}$. The value of RYP rose to around 0.75 and began to fluctuate. The fluid loss went down with the increasing of AM mass, while the variation was not obvious after $m(H E C): m(A M)=1: 4$. This illustrates that excessive AM grafting on HEC does not significantly improve the performance of bentonite composite. The result of the research suggest that the ratio of 1: 5 for HEC and AM was the optimal 
synthesis ratio.

HEC and AM were grafted in aqueous solution by using ammonium persulfate and sodium bisulfite as initiators. It was set that $\mathrm{pH}=7$, the monomer mass fraction was $10 \mathrm{wt} \%$, the mass ratio of $\mathrm{HEC}$ to $\mathrm{AM}$ was $1: 5$, and the reaction was performed at $60^{\circ} \mathrm{C}$ for $1 \mathrm{~h}$. The effect of the initiator in the range of $0.3-0.7 \mathrm{wt} \%$ was investigated (Figure 2c). It can be seen that the bentonite composite had the lowest fluid loss when the initiator concentration was $0.4-0.5 \mathrm{wt} \%$, while the RYP increased slowly after $0.5 \mathrm{wt} \%$ and even showed a downward trend. This may because at lower concentration of the initiator, fewer free radicals are generated, a "cage effect" is formed, and the initiation process is inefficient. [23] When the concentration of initiator is high, the polymerization speed is accelerated, and the polymer may agglomerate rapidly. [24] Both of the situations have a negative impact on the properties of the composite. Therefore, the initiator concentration was appropriately determined as $0.5 \mathrm{wt} \%$.

The effect of temperature on the properties of the composite is shown in Figure 2d. It was set that $\mathrm{pH}=7$, monomer mass fraction $10 \mathrm{wt} \%$, HEC to AM mass ratio $1: 5$, initiator $0.5 \mathrm{wt} \%$, and reaction at $40-60^{\circ} \mathrm{C}$ for $1 \mathrm{~h}$. It can be seen from Figure $2 \mathrm{~d}$ that the effect of temperature on the properties of the composite is not obvious. The bentonite composite showed the best filtration property at $45^{\circ} \mathrm{C}$, and the RYP also began to decrease after $45^{\circ} \mathrm{C}$. This may because the reaction rate is accelerated with the increasing temperature. [25] The viscosity of the polymer decreases with decreasing molecular weight. [26] As a result, the fluid loss of the composite went up and the RYP decreased. It was finally determined that the reaction temperature was $45^{\circ} \mathrm{C}$.

Microwave-assisted synthesis was used to study the effect in the range of 10-60min (Figure 2e). It was set that $\mathrm{pH}=7$, monomer mass fraction $10 \mathrm{wt} \%$, HEC to AM mass ratio $1: 5$, initiator $0.5 \mathrm{wt} \%$, temperature $45^{\circ} \mathrm{C}$. It is obvious that the RYP did not change significantly after $20 \mathrm{~min}$. The fluid loss decreased rapidly in the first 30 minutes, and rarely changed after 30 minutes. This indicates that under the action of microwave, the reaction was basically finished after $30 \mathrm{~min}$. Compared to traditional heating methods, microwaves could greatly save time. [27] The reaction time was determined to be $30 \mathrm{~min}$.

By changing the mass fraction of the reactant in the solvent (deionized water), the effect of the reactant concentration was studied (Figure 2f). It was set that $\mathrm{pH}=7$, the monomer mass fraction was $10 \mathrm{wt} \%$, the mass ratio of $\mathrm{HEC}$ to AM was 1:5, the initiator was $0.5 \mathrm{wt} \%$, and the reaction was performed at $45^{\circ} \mathrm{C}$ for 30 minutes. As shown in Figure 2f, the RYP of the bentonite composite slowly rised. As the reactant concentration increased, the filtration property of the composite became worse. The reactant concentration was determined to be $10 \mathrm{wt} \%$.

Eventually, the optimal synthesis conditions of the bentonite composite were determined as follows: $\mathrm{pH}=7$, initiator $0.5 \mathrm{wt} \%$, HEC to $\mathrm{AM}$ mass ratio $1: 5$, reaction temperature $45{ }^{\circ} \mathrm{C}$, reaction time $30 \mathrm{~min}$, and monomer mass fraction $10 \mathrm{wt} \%$.

\subsection{X-ray diffraction}

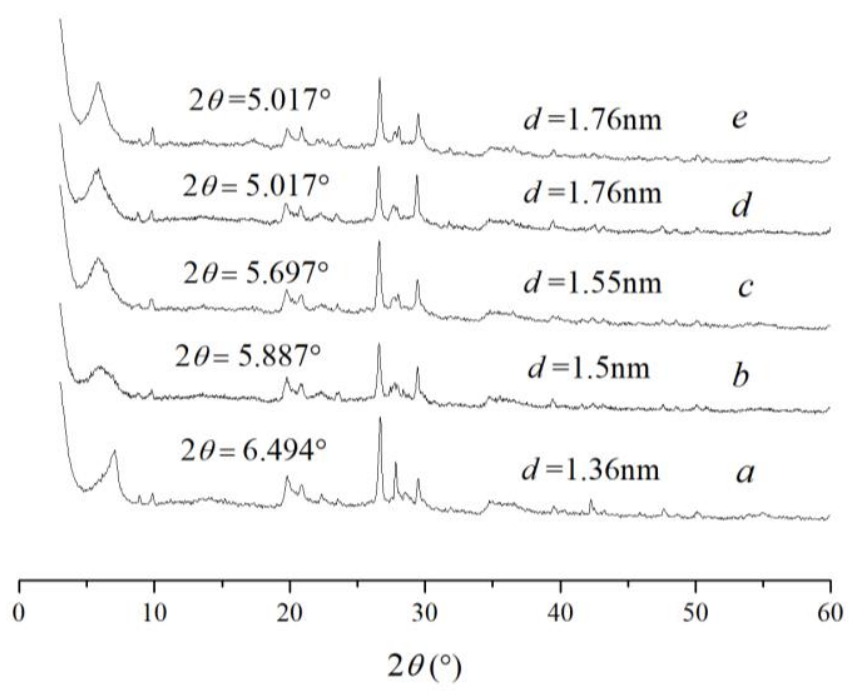

Figure 3: X-ray diffraction patterns of the samples: (a) original bentonite clay, (b) bentonite with 3\%HEC-AM, (c) bentonite with 4\%HEC-AM, (d) bentonite with 5\%HEC-AM and (e) bentonite with 6\%HEC-AM 
X-ray diffraction patterns of polymer-modified bentonite were tested at different polymer concentrations. Figure $3 \mathrm{a}$ is original bentonite, and Figures $3 \mathrm{~b}$-e are X-ray diffraction patterns of modified bentonite at concentrations of $3 \mathrm{wt} \%, 4 \mathrm{wt} \%, 5 \mathrm{wt} \%$, and $6 \mathrm{wt} \%$, respectively. The distance of the bentonite 001 crystal plane and the diffraction angle $2 \theta$ are shown in the figure. The interlayer distance of the original bentonite is $1.36 \mathrm{~nm}\left(\mathrm{~d}_{001}\right)$. However, for modified bentonite, the X-ray peak moved to a lower angle, which indicates that as HEC-AM enters the bentonite layer, the interlayer distance increase, up to $1.76 \mathrm{~nm}\left(\mathrm{~d}_{001}\right)$. Compared with the original bentonite, the layer of modified bentonite increased by $0.4 \mathrm{~nm}$. There are many - OH polar groups between the bentonite layers. When the HEC-AM aqueous solution is sheared at high speed, polar groups (such as $-\mathrm{CONH} 2$, etc.) in the HEC-AM can form hydrogen bonds with the $-\mathrm{OH}$ between the bentonite layers. The polymer was successfully intercalated between the bentonite layers under the internal driving force (hydrogen bonding) and external driving force (shearing force). [28] The final choice is to modify the bentonite with a polymer proportion of $5 \mathrm{wt} \%$.

\subsection{Infrared spectroscopy}

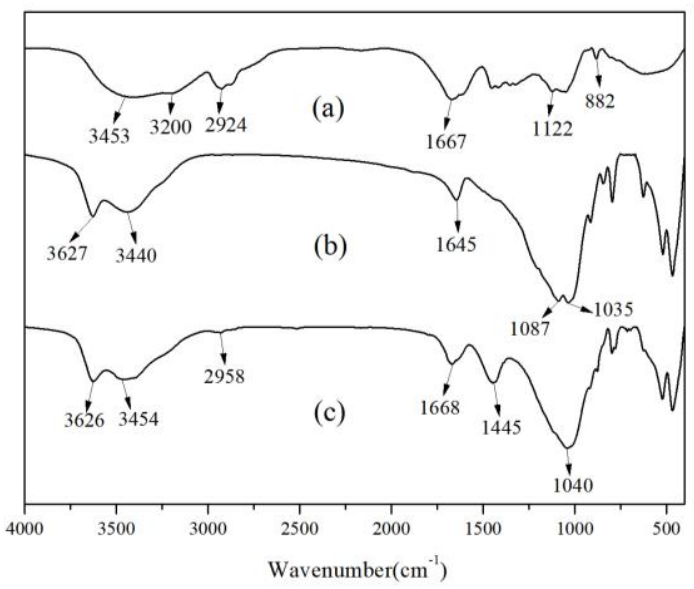

Figure 4: FT-IR spectra of (a) HEC-AM, (b) bentonite clay, (c) HEC-AM/bentonite

FT-IR analysis was used to confirm the preparation of HEC-AM/bentonite composite. Figure 4a shows the FT-IR spectrum of the HEC-AM graft polymer. It is found that $1068 \mathrm{~cm}^{-1}$ is the stretching vibration peak of cellulose ether $\beta$-(1,4)-diglycoside bond, and the peak near $1120 \mathrm{~cm}^{-1}$ is $\mathrm{C}-\mathrm{O}-\mathrm{C}$ in cellulose ether structure. The peak at $1667 \mathrm{~cm}^{-1}$ is the stretching vibration peak of $-\mathrm{CONH}_{2}$ in AM. The band at $2924 \mathrm{~cm}^{-1}$ is the result of asymmetric stretching of $\mathrm{C}-\mathrm{H}$ in the cellulose ether long chain. And the stretching vibration peak of primary amine in amide is $3200 \mathrm{~cm}^{-1}$. The peak at $3453 \mathrm{~cm}^{-1}$ belongs to the stretching vibration peak of the hydroxyl group affected by hydrogen bonding on HEC. Previous investigation by Xie et al. [29] observed similar bands in the polymers they synthesized. The grafted polymer contains linking units of HEC and AM, which proves that the grafted polymer was synthesized.

It can be clearly observed from Figures $4 \mathrm{~b}$ and $\mathrm{c}$ that new absorption bands have appeared at $1445 \mathrm{~cm}^{-1}$, $1668 \mathrm{~cm}^{-1}$ and $2958 \mathrm{~cm}^{-1}$. They are identified as $\mathrm{CH}_{2}$ bending vibration in the added $\mathrm{PAM}$ portion, $-\mathrm{C}=\mathrm{O}$ tensile vibration of the amide functional group, and asymmetric tensile vibration of $\mathrm{CH}_{2}$ separately. The broad peak is shown near $3310-3565 \mathrm{~cm}^{-1}$, which corresponds to the $-\mathrm{OH}$ tensile vibration in HEC. Compared with Figure $4 \mathrm{~b}$, the peak width around the vicinity of $1040 \mathrm{~cm}^{-1}$ in Figure $4 \mathrm{c}$ is wider, which may be due to the stretching vibration of $\beta$ - $(1,4)$-diglycoside bond in the added HEC. The FT-IR spectrum of the HEC-AM/bentonite composite meets the vibration peaks corresponding to the HEC-AM polymer and bentonite. 


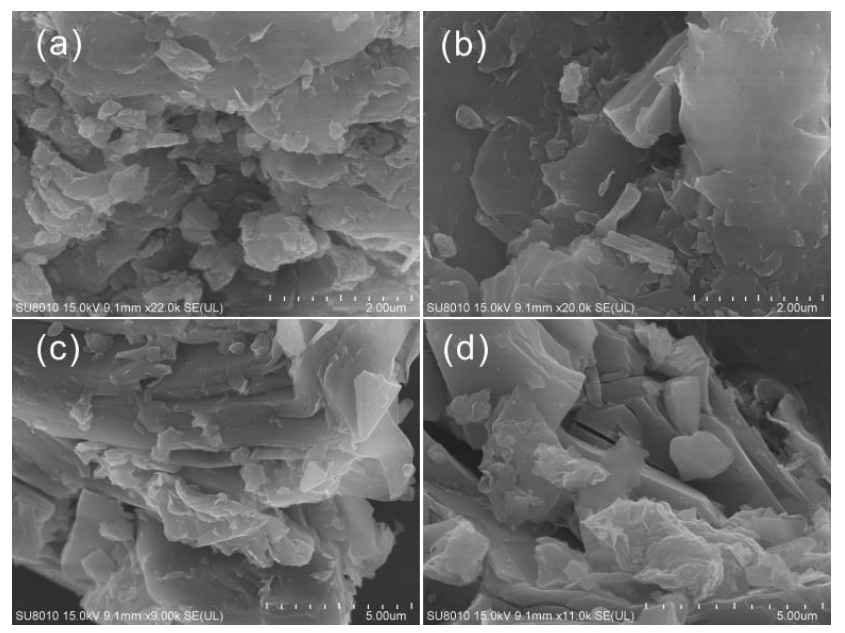

Figure 5: Scanning electron micrographs of (a) original bentonite, (b), (c) and (d) modified bentonite

As shown in Figure 5a, original Na-bentonite exists as aggregates of layered particles. It can be seen that the Na-bentonite is flat and arranged closely. For the modified Na-bentonite (Figures 5b, c, and d), the surface becomes rough and the layered structure is clearly stretched. This is the result of polymer HEC-AM intercalation. The polymer HEC-AM was first adsorbed on the surface of the layer, and intercalation occurred under the action of strong shear force. The bentonite particles seem to be "glued" together with the adsorption of $-\mathrm{CONH}_{2}$. [30] Compared with Na-bentonite (Figure 5a), the surface of the bentonite particles in Figures $c$ and $d$ changed significantly. Changes in the surface and interlayer of the bentonite can indicate that the composite was successfully prepared, which is consistent with X-ray diffraction data and FTIR spectroscopy analysis.

\subsection{Fluid rheological and filtration properties}

Table 1: Evaluation of rheological properties and fluid loss of natural Na-bentonite

\begin{tabular}{c|c|c|c|c|c}
\hline Conditions & $\eta_{\mathbf{A}}(\mathbf{m P a} \mathbf{s})$ & $\eta_{\mathbf{P}}(\mathbf{m P a} \cdot \mathbf{s})$ & $\boldsymbol{\eta}_{\mathbf{Y}}(\mathbf{P a})$ & $\mathbf{R Y P}$ & $\mathbf{F L}(\mathbf{m I})$ \\
\hline $25 \pm 3^{\circ} \mathrm{C} / 24 \mathrm{~h}$ & $13.5 \pm 0.6$ & $11.7 \pm 0.3$ & $1.9 \pm 0.2$ & $0.16 \pm 0.066$ & $21.5 \pm 0.29$ \\
\hline $90^{\circ} \mathrm{C} / 16 \mathrm{~h}$ & $18.8 \pm 1.3$ & $14.6 \pm 0.7$ & $4.3 \pm 0.5$ & $0.29 \pm 0.041$ & $24.0 \pm 0.29$ \\
\hline $120^{\circ} \mathrm{C} / 16 \mathrm{~h}$ & $22.1 \pm 0.6$ & $16.3 \pm 0.3$ & $6.0 \pm 0.4$ & $0.37 \pm 0.035$ & $26.1 \pm 0.14$ \\
\hline $150^{\circ} \mathrm{C} / 16 \mathrm{~h}$ & $24.7 \pm 0.3$ & $16.7 \pm 0.3$ & $8.2 \pm 0.3$ & $0.49 \pm 0.025$ & $29.0 \pm 0.26$ \\
\hline $180^{\circ} \mathrm{C} / 16 \mathrm{~h}$ & $29.2 \pm 0.3$ & $20.0 \pm 0.6$ & $9.4 \pm 0.4$ & $0.47 \pm 0.038$ & $32.4 \pm 0.30$ \\
\hline
\end{tabular}

Table 2: HEC-AM / Bentonite composite rheology and fluid loss evaluation

\begin{tabular}{c|c|c|c|c|c}
\hline Conditions & $\boldsymbol{\eta}_{\mathbf{A}}(\mathbf{m P a} \cdot \mathbf{s})$ & $\boldsymbol{\eta}_{\mathbf{P}}(\mathbf{m P a} \cdot \mathbf{s})$ & $\boldsymbol{\eta}_{\mathbf{Y}}(\mathbf{P a})$ & RYP & FL $(\mathbf{m l})$ \\
\hline $25 \pm 3^{\circ} \mathrm{C} / 24 \mathrm{~h}$ & $30.0 \pm 0.4$ & $18.0 \pm 0.4$ & $12.0 \pm 0.5$ & $0.64 \pm 0.026$ & $11.3 \pm 0.15$ \\
\hline $90^{\circ} \mathrm{C} / 16 \mathrm{~h}$ & $39.5 \pm 0.6$ & $24.0 \pm 0.6$ & $15.8 \pm 0.5$ & $0.66 \pm 0.036$ & $9.3 \pm 0.19$ \\
\hline $120^{\circ} \mathrm{C} / 16 \mathrm{~h}$ & $38.8 \pm 1.2$ & $27.0 \pm 0.9$ & $15.2 \pm 0.8$ & $0.62 \pm 0.056$ & $10.2 \pm 0.18$ \\
\hline $150^{\circ} \mathrm{C} / 16 \mathrm{~h}$ & $37.8 \pm 0.7$ & $21.0 \pm 0.4$ & $14.5 \pm 0.7$ & $0.60 \pm 0.059$ & $9.7 \pm 0.07$ \\
\hline $180^{\circ} \mathrm{C} / 16 \mathrm{~h}$ & $22.2 \pm 0.3$ & $17.0 \pm 0.6$ & $5.3 \pm 0.5$ & $0.31 \pm 0.035$ & $12.1 \pm 0.18$ \\
\hline
\end{tabular}

According to the recommended drilling bentonite test procedures, the rheological properties and fluid loss of natural Na-bentonite and HEC-AM/bentonite composites were evaluated (Table 1 and 2). It can be seen from the table that the apparent viscosity of natural Na-bentonite at room temperature is only about 13.5 
$\mathrm{mPa} \cdot \mathrm{s}$, which cannot reach the API standard of greater than $15 \mathrm{mPa} \cdot \mathrm{s}$. And it is obvious that natural bentonite has severely thickened at high temperatures. This indicates that high temperature has a great effect on natural $\mathrm{Na}$-bentonite. Compared with natural bentonite, the bentonite composite maintains stability in the range of $90-150^{\circ} \mathrm{C}$. The bentonite composite can still maintain a high RYP at high temperatures, so it has a good ability to carry cuttings. [31] Guo et al. [32] proved that RYP can reflect the ability of mud to carry cuttings. But bentonite composites may not be suitable for the situation above $150^{\circ} \mathrm{C}$.

As for the fluid loss property, the fluid loss of natural bentonite is high, and the variation range of its fluid loss is also unacceptable for drilling operations. At high fluid loss, formation may be polluted and the drill pipe may be stuck. [33] The bentonite composite controls fluid loss well, which can reach at 9.3ml. This may due to the polar groups (amide groups, etc.) in the bentonite composite. The above table shows the rheology and filtration properties of the bentonite composite. Other properties of the bentonite composite (such as lubricity, compatibility with drilling fluids, etc.) will be demonstrated in future research.

\section{CONCLUSIONS}

In this study, a HEC-AM graft polymer was synthesized by microwave, and hydroxyethyl cellulose-acrylamide graft polymer/bentonite composite was prepared by polymer solution intercalation. The preparation conditions of the bentonite composite were optimized by single-factor experiments. The polymer/bentonite composite were characterized using XRD analysis, FT-IR analysis and SEM analysis. Finally, the rheological properties and filtration properties of bentonite composite at different temperatures were evaluated. The analysis of the results leads to the following conclusions:

(1) The optimal synthesis conditions of HEC-AM grafted polymer/bentonite composite were determined as follows: $\mathrm{pH}=7$, the mass ratio of hydroxyethyl cellulose to acrylamide is $1: 5$, the concentration of the initiator is $0.5 \mathrm{wt} \%$, the temperature is $45{ }^{\circ} \mathrm{C}$, the reaction time is $30 \mathrm{~min}$, and the total concentration of the reactant monomer is $10 \mathrm{wt} \%$. With the assistance of microwave, the reaction completed in less time and with more uniformly heat.

(2) It can be seen from the XRD diffraction pattern that the spacing of modified bentonite layer is significantly increased, which is $0.4 \mathrm{~nm}$ more than the original bentonite. This indicates an intercalation behavior between the polymer and the bentonite. FTIR and SEM analysis showed that the polymer exists between the layers and the surface of the bentonite.

(3) The rheology of the bentonite composite is more stable than natural Na-bentonite. And bentonite composite can maintain high RYP (more than 0.6 ) at the temperature of $90-150^{\circ} \mathrm{C}$, which indicates that it has a stronger ability to carry drill cuttings. In terms of fluid loss, the bentonite composite performed better. Even at high temperatures, it can meet the standards of drilling-grade bentonite, with a minimum of $9.3 \mathrm{ml}$.

\section{ACKNOWLEDGEMENTS}

The authors appreciate the financial support from the National Natural Science Foundation of China(Grant No. 51974337); Liaoning Provincial Department of Education (Grant No. L2020026); China Petrolieum Science and Technology Innovation Fund (Grant No. 2017D-5007-0201).

\section{BIBLIOGRAPHY}

[1] AMORIM, L.V., BARBOSA, M.I.R., FERREIRA, H.C., "Bentonite/polymer compound development to application in drilling fluids - Part 2", Materia-Rio De Janeiro, v. 13. n. 1. pp. 209-219, 2008.

[2] SIMOES SILVA, S.S., NOBREGA, K.C., AMORIM, L.V., et al., "Evaluation of modified starches used in the mining for application in oil well drilling fluids", Materia-Rio De Janeiro, v. 24. n. 3. 2019.

[3] DE SOUZA, G.S., LUPORINI, S., RIGOLI, I.C., "Rheological characterization of saline clay dispersions with xanthan gum for oil well drilling fluids", Materia-Rio De Janeiro, v. 22. n. 1. 2017.

[4] MAHTO, V., SHARMA, V.P., "Characterization of Indian bentonite clay samples for water-based drilling fluids”, Petroleum Science and Technology, v. 26. n. 15. pp. 1859-1868, 2008.

[5] JAIN, R., MAHTO, V., "Evaluation of polyacrylamide/clay composite as a potential drilling fluid additive in inhibitive water based drilling fluid system”, Journal of Petroleum Science \& Engineering, v. 133. pp. 612-621, 2015. 
[6] MOHAMADIAN, N., GHORBANI, H., WOOD, D.A., et al., "A hybrid nanocomposite of poly(styrene-methyl methacrylate- acrylic acid) /clay as a novel rheology-improvement additive for drilling fluids", Journal of Polymer Research, v. 26. n. 2. 2019.

[7] ASHOKKUMAR, M., THANIKAIVELAN, P., KRISHNARAJ, K., et al., "Transforming Chromium Containing Collagen Wastes Into Flexible Composite Sheets Using Cellulose Derivatives: Structural, Thermal, and Mechanical Investigations", Polymer Composites, v. 32. n. 6. pp. 1009-1017, 2011.

[8] OUAER, H., GARECHE, M., "Hydroxyethyl cellulose as a rheology modifier for water-based drilling fluids formulated with Algerian bentonite", Journal of the Brazilian Society of Mechanical Sciences and Engineering, v. 41. n. 3. pp. 10, 2019.

[9] WANG, X.D., WU, M., ZHANG, B.M., et al., "Phase-transfer method synthesis hydroxyethyl cellulose lauryl ether", Colloids and Surfaces, A: Physicochemical and Engineering Aspects, v. 562. pp. 383-391, 2019.

[10] LUO, P.F., LIU, L.L., XU, W.Y., et al., "Preparation and characterization of aminated hyaluronic acid/oxidized hydroxyethyl cellulose hydrogel", Carbohydrate Polymers, v. 199. pp. 170-177, 2018.

[11] DING, C.F., LI, Y., WANG, Y.H., et al., "Highly selective adsorption of hydroquinone by hydroxyethyl cellulose functionalized with magnetic/ionic liquid", International Journal of Biological Macromolecules, v. 107. pp. 957-964, 2018.

[12] DIAO, Y.F., SONG, M.W., ZHANG, Y.L., et al., "Enzymic degradation of hydroxyethyl cellulose and analysis of the substitution pattern along the polysaccharide chain", Carbohydrate Polymers, v. 169. pp. 92-100, 2017.

[13] OUAER, H., GARECHE, M., "The rheological behaviour of a water-soluble polymer (HEC) used in drilling fluids", Journal of the Brazilian Society of Mechanical Sciences and Engineering, v. 40. n. 8. pp. 8, 2018.

[14] ZHAO, M., SHAO, Z., AO, L., "Performance, Application and Market Status of Hydroxyethyl Cellulose", Journal of Cellulose Science and Technology, v. 21. n. 2. 2013.

[15] WU, X.L., YAN, L.L., WANG, L.H., et al., "Progress in the Study of Environmentally Friendly Drilling Fluid Filtration Reducer", Drilling Fluid \& Completion Fluid, v. 35. n. 3. pp. 9, 2018.

[16] CHAUHAN, G.S., GULERIA, L., LAL, H., "Synthesis of graft copolymers of acrylamide and comonomers on to cellulose: A study of the effect of comonomer on polymer yields, structure and properties", Polymers and Polymer Composites, v. 11. n. 1. pp. 19-29, 2003.

[17] ZHANG, L.M., SUN, B.W., "Inhibition of water-soluble cationic cellulosic polymers to clay hydration", Journal of Applied Polymer Science, v. 74. n. 13. pp. 3088-3093, 1999.

[18] ZHOU, S., YANG, J., XU, F., Preparation and characterization of clay / hydroxyethyl cellulose layered composites, in 2015 National Polymer Academic Paper Report. Chinese Chemical Society, pp. 1453. Su Zhou 2015.

[19] ADAIR, A., KAESAMAN, A., KLINPITUKSA, P., "Superabsorbent materials derived from hydroxyethyl cellulose and bentonite: Preparation, characterization and swelling capacities", Polymer Testing, v. 64. pp. 321-329, 2017.

[20] WANG, J., GENG, D., YI, X., et al., "Study on the Evaluating Standard of Drilling Bentonite", Drilling Fluid \& Completion Fluid, v. 35. n. 6. 2018.

[21] DONG, W.X., PU, X.L., REN, Y.J., et al., "Thermoresponsive Bentonite for Water-Based Drilling Fluids", Materials, v. 12. n. 13. pp. 20, 2019.

[22] MA, X., ZHOU, Y., KOREAN, T., et al., "Synthesis and Indoor Evaluation of a Fluid Loss Additive with Significant Inhibition Effect", Fine Chemicals, v. 32. n. 7. 2015.

[23] YI, G., WANG, Y., KANG, Z., et al., "Preparation and swelling properties of hydrophylic-hydrophobic PVP-semi-IPN-PCL hydrogels", Journal of Chemical Industry and Engineering(China), v. 58. n. 10. 2007.

[24] DENG, L., LU, Y., WANG, J., "Causes and precautions of the implosion in the production of polyoxymethylene", China Synthetic Resin and Plastics, v. 31. n. 3. 2014.

[25] CHAUHAN, G. S., SHARMA, R., LAL, H., "Synthesis and characterization of graft copolymers of hydroxypropyl cellulose with acrylamide and some comonomers", Journal of Applied Polymer Science, v. 91. n. 1. pp. 545-555, 2004.

[26] DI MAIO, L., GAROFALO, E., SCARFATO, P., et al., "Effect of polymer/organoclay composition on morphology and rheological properties of polylactide nanocomposites", Polymer Composites, v. 36. n. 6. pp. 
1135-1144, 2015.

[27] GOVINDARAJ, B., SAROJADEVI, M., "Microwave-assisted synthesis and characterization of polyimide/functionalized MWCNT nanocomposites containing quinolyl moiety", Polymer Composites, v. 37. n. 8. pp. 2417-2424, 2016.

[28] YANG, S.C., GUO, M.Z., YANG, E.L., et al., "Study on Preparation and Performance of High Swelling Bentonite", Materia-Rio De Janeiro, v. 23. n. 3. pp. 8, 2018.

[29] XIE, L., YI, J., ZHANG, M., et al., "Solution Properties of HEC-AM Graft Polymer", Plastics, v. 40. n. 4. 2011.

[30] ZHONG, H.Y., QIU, Z.S., HUANG, W.A., et al., "Synergistic stabilization of shale by a mixture of polyamidoamine dendrimers modified bentonite with various generations in water-based drilling fluid", Applied Clay Science, v. 114. pp. 359-369, 2015.

[31] CHU, Q., LIN, L., "Synthesis and properties of an improved agent with restricted viscosity and shearing strength in water-based drilling fluid", Journal of Petroleum Science \& Engineering, v. 173. pp. 1254-1263, 2019.

[32] GUO, J., ZHAO, J., YANG, G., et al., "Research on Shear Thinning and Correlation of Drilling Fluid", Advances in Fine Petrochemicals, v. 16. n. 5. 2015.

[33] DAVOODI, S., RAMAZANI, S.A.A., SOLEIMANIAN, A., et al., "Application of a novel acrylamide copolymer containing highly hydrophobic comonomer as filtration control and rheology modifier additive in water-based drilling mud", Journal of Petroleum Science \& Engineering, v. 180. pp. 747-755, 2019.

\section{ORCID}

Songze Liao

Yi Pan

Shuangchun Yang

Guangzhi Liao

Minglei Xu

Dinar Nigmatullin https://orcid.org/0000-0002-7520-2980

https://orcid.org/0000-0002-0133-7778

https://orcid.org/0000-0002-2828-8590

https://orcid.org/0000-0001-7950-7549

https://orcid.org/0000-0002-4560-1366

https://orcid.org/0000-0003-0774-9615 